\title{
NOVAS PERSPECTIVAS DA RESPONSABILIDADE PROCESSUAL NO BRASIL: O PRINCÍPIO DA BOA-FÉ OBJ ETIVA E O DEVIDO PROCESSO LEGAL
}

THIAGO RODRIGUES DE PONTES BOMFIM 


\section{NOVAS PERSPECTIVAS DA RESPONSABILIDADE PROCESSUAL NO BRASIL: O PRINCÍPIO DA BOA-FÉ OBJ ETIVA E O DEVIDO PROCESSO LEGAL}

Thiago Rodrigues de Pontes Bomfim ${ }^{1}$

\section{RESUMO}

O presente estudo busca, inicial mente, demonstrar o caráter normativo dos princípi os constitucionais, bem como seu papel no que acaba por se transformar em uma nova ordem processual, para, por fim, uma vez reconhecido o caráter de princípio jurídico à boa-féobjetiva, situar seu fundamento constitucional em um novo conceito de devido processo legal.

Palavraschave Princípios. Normatividade. Boafé objetiva. Devido processo legal.

\section{ABSTRACT}

This study seeks to initially demonstrate the nomativity of the constitutional principles, as well as its role in eventually turn into a new procedural order, to finally, once recognized the legal character of theobjectivegood faith as principle, placeits constitutional foundation of a new concept of due process.

Keywords. Principles. Normativity. Objectivegood faith. Dueprocess of law. 


\section{INTRODUÇÃO}

O Direito Constitucional vemsofrendo nos últimos anos umamudança de perspectiva, representada, notadamente, por um movimento denominado neoconstitucionalismo, caracterizado, basicamente, pelo fortalecimento da idéia da força normativa da Constituição (aqui incluídos seus princípios e todas nomas atinentes aos direitos fundamentais), bem como pela ampliação da jurisdição constitucional (mista, no caso brasileiro) e, ai nda, pelo surgimento da necessidade de desenvolver uma nova hermenêutica constitucional, representada pela redefinição do papel desempenhado pelos princípios no ordenamento jurídico.

A doutrina brasileira já vem reconhecendo que o estudo do Direito Processual sofreu as influências desta transformação hermenêutica, renovação esta representada pelo fato de que “o processo volta a ser estudado a partir de uma perspectiva constitucional (o que não é novidade), mas agora seguindo esse novo repertório, que exige dos sujeitos processuais uma preparação técnica que Ihes permita operar com cláusulas gerais, princípio da proporcionalidade, controle difuso de constitucional idade de uma lei, etc².

Sobre essa modificação hermenêutica provocada pelo neoconstitucional ismo, bem como sua indiscutível repercussão no sistema processual, há quem sustente uma modificação na própria ideia de jurisdição, conceito este que deve passar

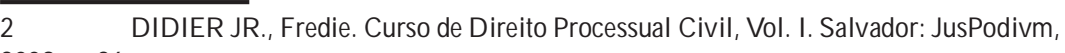
2009, p. 26. 
a ser compreendido e interpretado a partir dos princípios constitucionais e dos direitos fundamentais ${ }^{3}$.

Nessa linha, um tema que vem sendo discutido como concretização dessa nova real idade jurídica no sistema brasilei ro é o que se refere a boa-fé como princípio jurídico, em sua vertente objetiva, não como intenção ou estado de espírito, anal isados na pespectivasubjetiva. O presenteestudo propõese, portanto, a demonstrar, combase no quejá vem sendo discutido na literatura processual no Brasil, a existência do princípio da boafé objetiva, distinto do elemento subjetivo boa-fé, como exemplo dessa mudança de paradigma provocada pela influência do neoconstitucional ismo no direito processual.

\section{OS PRINCÍPIOS COMO NORMAS J URÍDICAS}

Como amplamente sabido, várias são as áreas do conhecimento que intentam a regulamentação das condutas sociais. Cadaumdessessetores dosaber possui val oressupremos, sintetizados em princípios, que são aplicados de acordo com as peculiaridades de cada uma das formas de controle da vida social, a exemplo da ética, da moral, da religião e do próprio direito.

Os princípios, que hoje povoam o imagi nário do direito

3 MARINONI, Luiz Guilherme. Curso de Direito Processual Civil, Vol. I, Teoria Geral do Processo. São Paulo: Editora Revista dos Tribunais, 2006, PP.44. Ressal te-se que o autor aqui citado reconhece com tal intensidade a influência do neoconstitucionalismo no direito processual, que dedica, na obra aqui destacada, um capítul o para o trato do fenômeno, bemcomo capítul os igual mente distintos para a função dos princípios constitucionais, bem como para a teoria dos direitos fundamentais. 
representam, em verdade, valores supremos para a realização humana, com um fundamento ético, moral ou religioso. As normas jurídicas nascem da observação social . O direito não cria suas normas em um laboratório hermético, alheio às vicissitudes da evolução social. O valor que a norma protege não é criado num passe de mágica no momento em que ela entra em vigor. $A$ evolução do sistema jurídico representa a evolução da proteção dos valores necessários ao mel hor controleda vidaemsociedade. Valores que se originam, muitas vezes, em outros campos do saber, posteriormente transformados em normas jurídicas.

Isto porque, embora a inobservância de qualquer norma de controle social gere a aplicação de uma sanção, esta somente será infligida de forma socialmente organizada no caso do descumprimento de uma noma jurídica, e não de qualquer norma de controle social, pelo fato de que somente a norma juńdica pode prever a possibilidade do uso da força quando seus preceitos forem descumpridos. Daí a necessidade de se transportar para o ordenamento jurídico os val ores éticos, morais, até mesmo religiosos, mais caros à sociedade, a fim lhes conferir uma proteção mais efetiva, já que o descumprimento de uma norma ética, moral ou religiosa não tem as mesmas consequências que a violação de uma normajurídica.

Esses valores, portanto, ingressam na ordem jurídica, abrigando-se sob a forma de princípios jurídicos, ora explícitos ora implícitos, convertendo o que era simplesmente um princípio ético, moral ou religioso, em um princípio juńdico, e, portanto, em uma norma juńdica. Há que se ressaltar que a 
utilização do termo princípio pelo sistema juńdico é feita com a mesma finalidade que a levada a efeito pelos outros campos do conhecimento, ou seja, para designar a estruturação de um sistema de ideias, pensamentos ou normas, por meio de um éxo, um ponto-chave de onde todos os pensamentos ou, no caso do sistema junídico, todas as normas derivam4. Assim, a diferença entre o tratamento dado pelo direito aos princípios não está na sua conceituação, mas em sua caracterização como norma jurídica, coercitiva, que, embora possa ter sua origem ligada a outros ramos do conhecimento humano, deixa de ser um comando puramente axiológico para ser al çado ao status de normajurídica enão simples i deal de vida ou puramente normas de comportamento humano sem qualquer tipo de imposição social mente organizada.

Dessa forma, para o sistema jurídico, o termo princípio ora é usado para designar a formulação dogmática de conceitos estruturados por sobre o direito positivo, ora para designar determinados tipos de normas juńdicas e ora para estabelecer os postulados teóricos, as proposições jurídicas construídas independentemente de uma ordem jurídica concreta ou de

$4 \quad$ Importante destacar que os princípios são classificados em várias categorias, a depender do papel a ser por eles desempenhado, tanto na doutrina portuguesa quanto na brasileira. J.J. Gomes Canotilho (Direito Constitucional e Teoria da Constituição, 7a Edição. Coimbra: Almedina, 2003, PP. 1165 e SS.), ao distinguir os princípios das regras, apresenta a seguinte tipol ogia: princípios jurídicos fundamentais, princípios políticos constitucionalmente conformadores, princípios constitucionais impositivos e princípios-garantia. Já Luís Roberto Barroso (Interpretação e Aplicação da Constituição. São Paulo: Saraiva, 2003) classifica os prinćípios em fundamentais, gerais e setoriais. Embora feito o registro, por necessário, não aprofundaremos mais o tema, uma vez que não constitui objeto do presente trabal ho. 
institutos de direito ou normas legais vigentes ${ }^{5}$.

No pensamento jurídico contemporâneo, tendo como paradigma no Brasil os estudos de Paulo Bonavides ${ }^{6}$, existe unanimidade, ao menos do ponto de vista doutrinário, em se reconhecer aos princípi osj unídicosstatus conceitual epositivo de norma dedireito, de normajurídica7. Nessalinha depensamento, os princípios são normas positivas, vinculativas, obrigam, têm eficácia positiva e negativa ${ }^{8}$ sobre comportamentos públicos ou privados bem como sobre a interpretação ea apl icação de outras normas, como as regraseoutros princípios derivadosdeprincípios mais abstratos. Reconhece-se, assim, nomatividade não só aos princípios que são, expressa e explicitamente, contemplados no âmago da ordem jurídica, mas também aos que, defluentes de seu sistema, são anunciados pela doutrina e descobertos no ato de aplicar o Direito 9 . A respeito da normatização sob a forma de princípios não-expressos, cuida Bobbio:

Aolado dos princípios geraisexpressosháosnão-expressos, ou seja, aqueles quese podemtirar por abstração denormas específicas ou pelo menos não muito gerais: são princípios,

\footnotetext{
5 ESPÍNDOLA, Ruy Samuel. Conceito de Princípios Constitucionais. 2002, pp. 55. 6 Emseu Curso de Direito Constitucional, precisamenteno capítul o 8, intitul ado “Dos Princípios Gerais de Direito aos Princípios Constitucionais".

$7 \quad$ ESPÍNDOLA, Ruy Samuel. Conceito de Princípios Constitucionais. 2002, pp. 60.

8 Segundo anota Ruy Samuel Espíndola, na obra citada na nota acima, "a expressão eficácia, em sentido negativo e positivo, está assim compreendida, no discurso do texto: por eficácia positiva dos princípios, entende-se a inspiração, a luz hermenèutica e normativa lançada no ato de aplicar o Direito, que conduz a determinadas soluções em cada caso, segundo a finalidade perseguida pelos princípios incidíveis no mesmo, por eficácia negativa dos princípios, entende-se que decisões, regras, ou mesmo, subprincípios que se contraponham a princípios serão inválidos, por contraste normativo".
}

9 ESPÍNDOLA, Ruy Samuel. Conceito de Princípios Constitucionais. 2002, pp. 61. 
ou normas generalíssimas, formul adas pelo intérprete, que busca col her, comparando normas aparentemente diversas entre si, aquilo a que comumente se chama o espírito do sistema ${ }^{10}$.

Ainda sobre a normatividade dos princípios, trata Crisafulli, citado por Espíndola:

Princípio é, com efeito, toda norma jurídica, enquanto considerada como determinante de uma ou de muitas outras subordinadas, que a pressupõem, desenvolvendo e especificando ulteriormente o preceito em direções mais particulares (menos gerais), das quais determinam e portanto, resumem, potencialmente, o conteúdo: sejam (...) estas efeivamente postas, sejam, ao contrário, apenas dedutíveis do respectivo princípio geral que as contêm ${ }^{11}$.

Na mesma linha entende Bobbio, que destaca que Os princípios gerais são, a meu ver, normas fundamentais ou general íssimas do sistema, as nomas mais gerais. O nome de princípios induz em engano, tanto que é velha questão entre juristas se os princípios são ou não são normas. Para mim não há dúvida: os princípios gerais são normas como todas as demais ${ }^{12}$.

Para Bonavides ${ }^{13}$, a normatividade dos princípios teria passado por três fases distintas. A primeira, jusnaturalista, posiciona-os em esfera abstrata e metafísica, tratando-os como inspiradores de um ideal de justiça, cuja eficácia cinge-se a uma

\footnotetext{
10 BOBBIO, Norberto. Teoria do Ordenamento J urídico. 1999, pp. 159.

11 ESPÍNDOLA, Ruy Samuel. Conceito de Princípios Constitucionais. 2002, pp. 61.

12 BOBBIO, Norberto. Teoria do Ordenamento J urídico. 1999, pp. 158.

13 BONAVIDES, Paulo. Curso de Direito Constitucional. 1994, pp. 232 ess.
} 
dimensão ético-val orativa do direito. Essa corrente concebe os princípios gerais de direito como axiomas jurídicos ou nomas estabelecidas pela reta razão. Na segunda fase, juspositivista, os princípios ingressam nas codificações como mera fonte subsidiária da inteireza dos textos legais. Não são encarados como superiores às leis, mas delas deduzidos, para fins de suprir eventuais vazios normativos quenão puderamprever. O val or dos princípios está no fato de derivarem das leis, e não de um ideal de justiça, o que torna altamente precária sua normatividade, por conta do papel subsidiário que essa corrente lhes atribui e o lugar teórico em que Ihes coloca, como fontes de integração do direito, isso na hipótese de ocorrerem vazios legais. A terceira e última fase, a do pós-positivismo, inaugurou-se em fins do último século, a partir da hegemonia axiológico normativa conquistada pelos princípios, que, uma vez positivados nos novos Textos Constitucionai $\mathrm{s}^{14}$, informam a compatibilidade fundamentadora da ordem jurídica de acordo com os princípios constitucionais, que dão fundamento axiológico e normativo ao ordenamento jurídico ${ }^{15}$. Nesta fase, observa Espíndola, os princípios jurídicos conquistam a digni dade de normas juńdicas vinculantes, vigentes e eficazes para muito além da atividade integratória do direito ${ }^{16}$.

\footnotetext{
14 Sobreo tema, J.J. Gomes Canotil ho (Direito Constitucional eTeoria da Constituição, 7 ạ Edição. Coimbra: Almedina, 2003, PP. 26), destaca a viragem jurisprudencial do direito constitucional, ressal tando que as decisões dos tribunais constitucionais passaram a considerarse como um novo modo de praticar o direito constitucional - daí o nome de moderno direito constitucional.

15 Conforme trabalha Ruy Samuel Espíndola, em seu Conceito de Princípios Constitucionais, sobre a teorização de Paulo Bonavides.

16 ESPíNDOLA, Ruy Samuel. Conceito de Princípios Constitucionais. 2002, pp. 64.
} 
Eis como encara Bonavides o ingresso dos princípios na fase atual em que seencontram, denominada pós-positivismo:

\begin{abstract}
A passagem dos princípios da especulação metafísica e abstrata para o campo concreto e positivo do Direito, com baixíssimo teor de densidade normativa; a transição crucial da ordem jusprivatista (sua antiga inserção nos códigos) para a órbita juspublicística (seu ingresso nas Constituições); a suspensão da distinção clássica entre princípios e normas; o deslocamento dos princípios da esfera da jusfilosofia para o domínio da Ciência Jurídica; a proclamação de sua normatividade; a perda de seu caráter de normas programáticas; o reconhecimento definitivo de sua positividade e concretude por obra sobretudo das Constitui ções; a distinção entre regras e princípios, como espécies diversificadas do gênero norma, e, finalmente, por expressão máxima detodo esse desdobramento doutrinário, o mais significativo de seus efeitos: a total hegemonia e preaminência dos princípios ${ }^{17}$.
\end{abstract}

No entender de Espíndola, o caminho percorrido pelos princípios até o estágio atual, representa a evolução da servil normatividade no Direito Privado à senhora juridicidade no Direito Público"18.

Sobre a temática dos princípios, como princípios gerais do direito e princípios constitucionais, o substrato das maiores discussões que levaram ao estágio atual da compreensão sobre os princípios constitucionais é creditado, no Brasil, como dito, a Paulo Bonavides, em seu Curso de Direito Constitucional,

17 BONAVIDES, Paulo. Curso de Direito Constitucional. 1994, pp. 265.

18 ESPÍNDOLA, Ruy Samuel. Conceito de Princípios Constitucionais. 2002, pp. 65.

Revista Esmat, Palmas, Ano 4, no 4, pag. 301 a 331 - jan/dez 2012 
notadamente em seu capítulo 8, intitulado “Dos Princípios Gerais do Direito aos Princípios Constitucionais".

Segundo o festejado constitucionalista cearense, como também observado por Espíndola, a importância dos princípios gerais do direito, para a compreensão do Estado de Direito contemporâneo, agravou-se a partir do advento da teoria material da Constituição ${ }^{19}$, que os reformulou teoricamente, introduzindo-os nos Textos Constitucionais e reformulando-os na dupl a dimensão de normatividade e constitucional idade ${ }^{20}$.

Os val ores fundamentais para a sociedade, condensados nos princípios, serão realizados através do reconhecimento da positividade dos mesmos, a fim de criar o que o autor denomina Estado principialista, que seria uma versão mais refinada e aperfeiçoada de Estado de Direito ${ }^{21}$. Segundo Bonavides, o Estado somente será principialista se estiver fundado na positividade dos valores da justiça, da razão, da liberdade, da igual dade e da democracia, com os quais os princípi os mesmos da ordem jurídica fundamental se identificam ${ }^{22}$. Dessa forma, os princípios gerais de di reito passam a residir na Constituição, expressa ou implicitamente, desde que a Constituição seja a de

\footnotetext{
19 Por não ser objetivo primordial denosso trabal ho, não nos detivemosemprofundidade sobre o tema. Para uma mel hor compreensão sobre o que entende o autor sobretal teoria, vide o seu Curso de Direito Constitucional.

20 ESPÍNDOLA, Ruy Samuel. Conceito de Princípios Constitucionais. 2002, pp. 131132.

21 Ruy Samuel Espíndola observa que "tendo-se em conta o preâmbulo, o tít I da Constituição vigente, pode-se concluir que o Estado brasileiro, através da análise de Bonavides, enquadra-se como Estado principialista, pois consagra, ao menos textual mente, os val ores por ele profligados", em seu Conceito de Princípios Constitucionais. 2002, pp. 132, nota n 69.

22 BONAVIDES, Paulo. Curso de Direito Constitucional. 1994, pp. 18.
} 
um Estado principialista. A constitucional ização dos princípios seria o "axioma juspublicístico de nosso tempo" e que os princípios constitucionais nada mais são, em seu fundamento teórico, do que os princípios gerais do direito restituídos à sua dimensão intrínseca de valores superiores. Nessa linha, sustenta que os princípios "operaram nos textos constitucionais da segunda metade deste sécul o uma revolução de juridici dade sem precedente nos anais do constitucionalismo. De princípios gerais se transformaram, já, em princípi os constitucionais"23.

Sobre a importância da construção teórica de Paulo Bonavides para a compreensão atual da posição normativa ocupada pelos princípios, cuida Espíndola:

O ponto central desse movimento de transformação normativa, por que passaram os princípios, reside, em rigor, no caráter e no lugar de sua normatividade, depois que "saltaram" dos Códigos para as Constituições, do Direito Privado para o Direito Público. Esse salto alterou as funções dos princípios no Direito Positivo, os quais, antes, nos albores do século XIX, durante as codificações, desempenhavamo papel de fontes de mero teor supletório, como princípios gerais de caráter civilístico, e, agora, a partir de meados do sécul o XX, atuam como fundamentos de toda a ordem jurídica, na qualidade de princípios constitucionais. A constitucionalização dos princípios operou, assim, verdadeira revolução princi pial ${ }^{24}$.

Dessa maneira, em se considerando a evolução dos princípios gerais de direito para o patamar de princípios 
constitucionais, há que se reler as funções desempenhadas pelos princípios nessa nova ordem, já que a antiga finalidade meramente integrativa ${ }^{25}$ preconizada pela Le de Introdução ao Código Civil não representa mais o único papel desempenhado pelos princípios, na medida em que houve a inversão, como já mencionadoacima, dostatusdosprincípi osdesupl etivodelacunas legisl ativas para fundantes da ordemjurídi ca". Isto porque "Sea lei passa a se subordinar aos princípios constitucionais de justiça eaos di reitos fundamentais, a tarefa da doutrina deixa deser a de simplesmente descrever a lei. Cabeagora ao jurista, seja qual for aárea desua especial idade, em primeiro lugar compreender a lei àluz dos princípi os constitucionai se dos direitos fundamentai $\mathrm{s}^{27}$.

Como destacam Bonavides ${ }^{28}$ e Espíndola29, os princípios cumpririam três funções relevantes na ordem juńdica: fundamentadora, interpretativa e supletiva. Através da função fundamentadora, os princípios ostentam uma eficácia derrogatória e diretiva. Essa função ocupa enorme importância no Direito Público, especialmente no Direito Constitucional contemporâneo. Por conta dessa função, as normas que se

\footnotetext{
$25 \quad$ Art $4^{\circ}$ - Quando a lei for omissa, o intérprete se utilizará de anal ogia, costumes e princípios gerais de di reito.

26 J.J. Gomes Canotilho (Direito Constitucional e Teoria da Constituição, 7ạ Edi ção. Coimbra: Almedina, 2003, PP. 1160), utiliza, dentre outros, como critério distintivo entre regras e princípios o caráter de fundamentali idade no sistema das fontes de direito, segundo o qual os princípios são normas de natureza estruturante ou com um papel fundamental no ordenamento jurídico devido à sua posição hierárquica no sistema das fontes (ex.: princípios constitucionais) ou àsua importância estruturante dentro do sistemajurídico (ex.: princípio do Estado deDireito). 27 MARINONI, Luiz Guil lherme. Curso deDireito Processual Civil, Vol. I, Teoria Geral do Processo. São Paulo: Editora Revista dos Tribunais, 2006, PP.45.

28 BONAVIDES, Paulo. Curso de Direito Constitucional. 1994, pp. 254 ess.

29 ESPÍNDOLA, Ruy Samuel. Conceito de Princípios Constitucionais. 2002, pp. 72.
} 
contraponham aos núcleos de irradiação normativa assentados nos princípios constitucionais, perderão sua val idade e/ou sua vigência ${ }^{30}$ em face de contraste normativo com normas de patamar constitucional ${ }^{31}$.

Já pela função interpretativa, os princípios cumprem o papel de orientar as soluções jurídicas a serem definidas em face dos casos submetidos à apreciação do intérprete. São vetores de sentido jurídico às demais normas, em face dos fatos e atos que exijam compreensão normativa. Assim, cumprem função orientadora do trabalho interpretativo, através dos núcleos de sentido deduzíveis dos princípios jurídicos ${ }^{32}$.

No caso da função supletiva, realizam o trabal ho de integração do sistema juńdico, suplementando os eventuais vazios nomativos da ordem jurídica ou ausências de sentido regul ador constatáveis em regras ou em princípi os demai or grau de densi dade normativa ${ }^{33}$.

Não obstante, é possível que um princípio desempenhe tanto função fundamentadora como interpretativa. O quese deve definitivamente repisar é que a pura e simples função supletiva, outrora dominante, não pode ser vista como regra nesse novo contexto neoconstitucional ista ou pós-positivista34.

30 Os conceitos de validade e vigência, por não consistirem em tema próprio deste trabal ho, não são tratados com profundi dade. A penas são citados para demonstrar a conseqüência da violação a um princípio constitucional.

31 ESPÍNDOLA, Ruy Samuel. Conceito de Princípios Constitucionais. 2002, pp. 72.

32 ESPÍNDOLA, Ruy Samuel. Conceito de Princípios Constitucionais. 2002, pp. 73.

33 ESPÍNDOLA, Ruy Samuel. Conceito de Princípios Constitucionais. 2002, pp. 73.

34 Expressão utilizada por Paulo Bonavides ejá conceituada anteriormente. 


\section{PAPEL DOS PRINCÍPIOS CONSTITUCIONAIS NA ORDEM PROCESSUAL}

De acordo com o que foi exposto acima, percebese claramente que, diante da compreensão atual de sistema juńdico no Brasil, notadamente pelo papel desempenhado pelos princípios, a Constituição passa a cumprir uma função essencial no sistema processual. Isto porque os princípios constitucionais aplicáveis ao processo passam a atuar na fundamentação, interpretação e integração do sistema processual, assumindo papel deestruturação, construção e fecundação do ordenamento instrumenta ${ }^{35}$.

Assim a doutrina brasileira já vem reconhecendo a existência de um ordenamento processual civil aberto, formado por regras e princípios processuais, princípios estes que representam a síntese dos valores históricos mais caros à sociedade e que refletem no direito instrumental. Assim, os princípios gerais do processo assumem através de suas funções, a posição de relevância, na formação do ordenamento processual, e, consequentemente, na atuação da função jurisdicional ${ }^{36}$. Isto porque, o processo deve estar adequado à tutela efetiva dos direitos fundamentais (di mensão subjetiva) e, além disso, ele próprio deve ser estruturado de acordo com os

\footnotetext{
$35 \quad$ MENDONÇA JR., Delosmar. Princípio Constitucional da Duração Razoável do Processo, in Constituição e Efetividade Constitucional. Sal vador: JusPodivm, 2008, PP.26.

36 MENDONÇA JR., Delosmar. Princípio Constitucional da Duração Razoável do Processo, in Constituição e Efetividade Constitucional. Salvador: J usPodivm, 2008, PP.26.
} 
direitos fundamentais (dimensão objetiva) ${ }^{37}$.

Comojávistoosval oresconstitucionalmenteassegurados, representados pelos princípios, irradiam-se por todo o sistema jurídico, definindo princípios e regras aplicáveis a cada ramo do Direito, com base nos ditames estruturados pela Constitui ção. Nessa linha, o sistema processual concretiza os valores contidos na Carta Magna através da atividade jurisdicional ${ }^{38}$, definindo os princípios estruturantes do sistema processual, que vai passar a atuar de acordo com o que foi previamente estabelecido e delimitado pelo Texto Constitucional. Há quem sustente, inclusive, na doutrina brasileira, o surgimento de um neoprocessualism ${ }^{39}$. Assim, os princípios constitucionais do processo legitimama ordem processual, em razão dos escopos da Constitui ção, e a observância desses princípios, na atuação das normas constitucionais, contribui para a legitimação da Constituiçãa $0^{40}$.

Sobre o tema, destaca Calmon de Passos, citado por Delosmar Mendonça J r.: só é legítimo Estado de Direito aquele que defere aos indivíduos direitos que a ele Estado possam

37 DIDIER JR., Fredie. Curso de Direito Processual Civil, Vol. I. Salvador: J usPodivm, 2009, pp.27. Na mesma linha, FREIRE, Ricardo Maurício. O princípio constitucional da dignidade da pessoa humana. São Paulo: Saraiva, 2010, PP. 181, para quem “o processo passa a apresentar maior maleabilidade em face das especificidades de cada lide, adaptando os procedi mentos às exigências axiológicas e val orativas dos direitos fundamentais envolvidos nas lides.

38 MENDONÇA JR., Delosmar. Princípio Constitucional da Duração Razoável do Processo, in Constituição e Efetividade Constitucional. Salvador: J usPodivm, 2008, PP.27.

39 DIDIER J R., Fredie. Curso de Direito Processual Civil, Vol. I. Sal vador: J usPodivm, 2009, pp.26.

40 MENDONÇA JR., Delosmar. Princípio Constitucional da Duração Razoável do Processo, in Constituição e Efetividade Constitucional. Salvador: J usPodivm, 2008, PP.27. 
ser oponíveis. E esses direitos fundamentais, para que sejam exaustivos, devemnão só dizer respeito à segurança econômica dos cidadãos. E apenas serão efetivamente direitos se providos de instrumentos, tambémconstitucionalmente assegurados, que Ihes permitam sempre se fazer efetivos" ${ }^{41}$. O processo " convertese, assim na instituição jurídica do exercício dos direitos fundamentais na construção da estrutura (espaço-tempo) do procedimento ${ }^{42}$.

\section{PRINCÍPIO DA BOA-FÉ OBJETIVA NO SISTEMA J URÍDICO BRASI LEIRO}

No direito brasileiro a discussão a respeito da boafé objetiva ganhou corpo, inicialmente, no âmbito do Direito Civil, onde se reconheceu a necessidade de observância da lealdade e confiança recíprocas em toda a fase pré-contratual. Posteriormente, a boafé objetiva ultrapassa as tratativas negociais, atingindo fases subseqüentes da relação contratual, surgindo como princípio que permite a construção de uma noção substancial ista do direito e, no Direito Civil eComercial, encontra-se geral mente consagrado em uma cláusula geral cujo objetivo éa eticização das relações juńdi cas ${ }^{43}$.

Emque pese o Código Civil brasileiro de 1916 não tratar

\footnotetext{
41 MENDONÇA JR., Delosmar. Princípio Constitucional da Duração Razoável do Processo, in Constituição e Efetividade Constitucional. Salvador: J usPodivm, 2008, PP.28.

42 FREIRE, Ricardo Maurício. O princípio constitucional da dignidade da pessoa humana. São Paulo: Saraiva, 2010, PP.182.

43 CARVALHO, Raquel Melo Urbano de. Curso de Direito Administrativo. Salvador: J usPodivm, 2008, PP.110.
} 
especificamente sobre o tema, o Código Comercial já o fazia desde 1850, prevendo a boafé objetiva como cláusula geral e, portanto, como paradigma fundamental de interpretação dos negócios jurídicos. Na mesma linha, o Código de Defesa do Consumidor (Lei Federal 8.078/90) expressamente destaca a boa-fé (arts. 40, III e 51, IV44), além de a ela fazer referência indireta em seu art. 37, quando veda a publicidade enganosa. O Novo Diploma Civil brasileiro, de 2002, ao contrário do anterior, expressamente alude à necessidade de observância da boafénos negócios jurídicos, notadamente nos arts. 422 e $113^{45}$, estabelecendo, por fim, o artigo 187 que aquele que, ao exercer seu direito, exceda manifestamente os limites impostos pela boa-fé cometeato ilícito, uma vez que, ao assim proceder, abusa do direito que lhe fora reconhecido.

A introdução de tais regras no sistema jurídico brasileiro

\footnotetext{
$44 \quad$ Art 40A Política Nacional das Relações de Consumo tempor objetivo o atendimento das necessidades dos consumidores, o respeito à sua dignidade, saúde e segurança, a proteção de seus interesses econômicos, a mel horia da sua qualidade de vida, bem como a transparência e harmonia das relações de consumo, atendi dos os seguintes princípi os: (Redação dada pela Lè ํo9.008, de 21.3.1995)

[...]

III - harmonização dos interesses dos participantes das rel ações de consumo e compati bilização da proteção do consumidor com a necessidade de desenvol vimento econômico etecnológico, de modo a viabilizar os princípi os nos quais se funda a ordem econômica (art. 170, da Constitui ção Federal), semprecombasena boa-fée equilíbrio nas relações entreconsumi dores efornecedores; Art. 51. São nul as de pleno direito, entreoutras, as cláusul as contratuais relativas ao fornecimento de produtos e serviços que:

[...]

IV - estabeleçam obrigações consideradas iníquas, abusivas, que coloquem o consumidor em desvantagem exagerada, ou sejam incompatívés com a boafé ou a eqüi dade;

45 Art 113. Os negócios jurídicos devem ser interpretados conforme a boafée os usos do lugar de sua celebração.

Art. 422. Os contratantes são obrigados a guardar, assim na concl usão do contrato, como em sua execução, os princípios de probidadee boafé.
} 
tornaram a boa-fé objetiva, antes um valor meramente axiológico, em um standard juridicamente consagrado, o qual impõe um padrão ético de honestidade, confiança, lealdade e fidelidade àqueles vinculados em um dado negócio jurídico ${ }^{46}$.

A consagração, portanto, do princípio da boa-fé objetiva resulta de um alargamento da exigência de boa-fé do direito privado ao direito público, caminho seguido pela doutrina, fazendo com que a boa fé objetiva se expandisse para todos os ramos jurídicos ${ }^{47}$. Especificamente no Direito Processual Civil, o princípio da boafé podeser extraído do inciso II , do art. 14, do Código de Processo Civil brasileiro: “Art. 14. São deveres das partes e de todos aqueles que de qual quer forma participem do processo: (...) II-proceder com lealdade e boa-fé", destacandose que boa-fé, nesse caso, deve ser entendida como uma norma de conduta, ou boa-fé objetiva ${ }^{48}$.

I mportanteatentar para o fato de que o comando contido no dispositivo destacado acima tem como destinatários todos aqueles que de qualquer forma participam do processo, o que inclui, por óbvio, não só as partes da relação processual, mas também o órgão jurisdicional. Isto porque a vinculação do

46 CARVALHO, Raquel Melo Urbano de. Curso de Direito Administrativo. Salvador: J usPodivm, 2008, PP.110.

47 DIDIER J R., Fredie. Curso de Direito Processual Civil, Vol. I. Salvador: J usPodivm, 2009, pp.46, bem como Rizzatto Nunes, O Princípio Constitucional da Dignidade da Pessoa Humana. São Paulo: Saraiva, 2010, PP. 75, que afirma: "Anote-se, bem, a boa-fé objetiva é fundamento de todo sistema jurídico, de modo que ela pode e deve ser observada em todo tipo de relação existente, é por ela que se estabel ece um equil líbrio esperado para a rel ação, qual quer que seja esta.

48 Observação feita por DIDIER JR., Fredie. Curso de Direito Processual Civil, Vol. I. Sal vador: J usPodivm, 2009, pp.45. 
Estado-juiz ao dever de boa-fé nada mais é senão o reflexo do princípio de que o Estado, tout court, deve agir de acordo com a boa-fé e, pois, de maneira leal e com proteção à confiança ${ }^{49}$.

Outra característica do princípio aqui aludido é o fato de que se trata de uma cláusula geral processual. Uma vez que a infinidade de situações que podem surgir no decorrer do processo poderia gerar a ineficácia de enumeração legal exaustiva das hipóteses de comportamento desleal, correta é a opção da legislação brasileira por uma noma geral que impõeo comportamento de acordo com a boafé. Em verdade, não seria necessária qual quer enumeração das condutas desl eais: o inciso II do art 14 do CPC brasileiro ébastante, justamentepor setratar de uma cláusula geral ${ }^{50}$. Para al guns autores, a boa-fé objetiva seria, ainda, "um modelo principiológico que visa garantir a ação e/ou conduta sem qualquer abuso ou nenhum tipo de obstrução ou, ainda, lesão à outra parteou partes envol vidas na relação, tudo de modo a gerar uma atitude cooperativa ${ }^{51}$.

Ponto que igual mente merece destaque é a necessidade de distinguir o princípio da boafé (na condição de norma) da exigência de boafé (elemento subjetivo) para a configuração de alguns ilícitos processuais, como o manifesto propósito protelatório, que possi bilita a anteci pação dos efeitos da tutel $a^{52}$,

49 DIDIER J R., Fredie. Curso de Direito Processual Civil, Vol. I. Salvador: J usPodivm, 2009, pp.46.

50 Observação anotada por Fredie Didier J r. em seu Curso de Direito Processual Civil, Vol. I. Salvador: JusPodivm, 2009, pp.46.

51 Rizzatto Nunes, O Princípio Constitucional da Digni dade da Pessoa Humana. São Paulo: Saraiva, 2010.

52 Segundo al erta Fredie Didier J r., em seu Curso de Direito Processual Civil, Vol. I. Sal vador: J usPodivm, 2009, pp.46. 
tal qual previsto no art. 273, II, do Código de Processo Civil brasileiro53. A boafé subjetiva é elemento do suporte fático de certos fatos jurídicos, ou seja, é fato. Já a boafé objetiva é uma norma de conduta que, em tal condição, impõe e proíbe condutas, além de criar situações junídicas ativas e passivas. Como alerta o processual ista baiano Fredie Didier J r., não existe princípio da boa-fé subjetiva. O inciso II do art 14 do CPC brasileiro não está relacionado à boa-fé subjetiva, à intenção do sujeito do processo; trata-se de norma que impõe condutas em conformidade com a boa-fé objetivamente considerada, independentemente da existência de boas ou más intençõe ${ }^{54}$.

Segundo a doutrina, a aplicação da boafé ao processo pode ser sistematizada em quatro hipóteses ${ }^{55}$. A primeira delas é a proibição de criar dolosamente posições processuais, ou seja, proibição de agir de máfé, como no caso de alguns exemplos previstos no Código de Processo Civil brasileiro, a saber, o requerimento doloso da citação por edital (art. 233); a atuação dolosa do órgão jurisdicional (art. 133,I); e algumas hipóteses de litigância de má-fé que exigem a presença do "elemento subjetivo" (art. 17, I, II , III e IV) ${ }^{56}$.

53 Art. 273. O juiz poderá, a requerimento da parte, anteci par, total ou parcialmente, os efeitos datutela pretendida no pedido inicial, desdeque, existindo prova inequívoca, seconvença da verossimilhança da al egação e (Redação dada pela Le ํㅡㅇ.952, de 13.12.1994)

II - fique caracterizado o abuso de direito de defesa ou o manifesto propósito protelatório do réu. (Incluído pela Lei no 8.952, de 13.12.1994)

54 DIDIER J R., Fredie. Curso de Direito Processual Civil, Vol. I. Salvador: J usPodivm, 2009, pp.46.

55 A sistematização aqui abordada é feita na doutrina brasileira por Fredie Didier Jr., que anota semel hante formul ação difundi da na literatura portuguesa por Menezes Cordeiro.

56 Fredie Didier J r. destaca que nem todos os casos de litigância de máfé previstos no CPC brasileiro exigem a máfé "subjetiva”, havendo hi póteses em que a "máfé" é examinada 
Outro caso de aplicação da boafé ao processo é a proibição de venire contra factum proprium, ou seja, atuação contraditória ao longo do processo. Em que pese nunca ter sido objeto de previsão expressa no ordenamento, "apesar do silêncio da lei, promovida uma interpretação liberta das amarras positivistas, percebese que o venire contra factum proprium é consectário natural da repressão ao abuso de direito, sendo perfeitamente aplicável no direito brasileiro" 57 . Em síntese, "é a consagração de que ninguém pode se opor a fato a que ele próprio deu causa" ${ }^{58}$. Impende destacar que o venire contra factum proprium pode se verificar tanto diante de comportamentos comissivos quanto omissivos, ou seja, tanto quando uma das partes cria a confiança de que determinada conduta será adotada, e não o é, quanto no caso em que a confiança é no sentido de que aquele comportamento não será adotado, mas termina sendo ${ }^{59}$. Como por exemplo, recorrer de uma decisão que se aceitou (art 503) ou pedir a inval idação de ato a cujo defeito deu causa (art. 243). Como anotado acima, o princípio da boafé objetiva aplica-se, também, ao órgão jurisdicional, e não apenas às partes, razão pela qual pode

objetivamente, como ocorre no caso dos incisos $\mathrm{V}$ (proceder de modo temerário em qual quer incidente ou ato do processo; VI (provocar incidentes manifestamente infundados) e VII (interpuser recurso com intuito manifestamente protelatório) do art. 17 do referido Diploma Legal.

57 ROSENVALD, NelsoneFARIAS, Cristiano Chaves de. Direito Civil - TeoriaGeral. Rio deJ aneiro: Editora Lumen Juris, 2007, PP.518.

58 ROSENVALD, NelsoneFARIAS, Cristiano Chaves de. Direito Civil - TeoriaGeral. Rio deJ aneiro: Editora Lumen J uris, 2007, PP.518.

59 Observação feita por ROSENVALD, Neson e FARIAS, Cristiano Chaves de Direito Civil - Teoria Geral. Rio de J aneiro: Editora Lumen Juris, 2007, PP.520. 
também aquele violar a boafé objetivamente posta na vertente aqui abordada, como éo caso do juiz quejul ga anteci padamente o feito al egando que nos autos apenas consta prova documental e, contraditoriamente, julga a pretensão improcedente afirmando que não há nos autos provas das al egações.

Háqueseanotar, ainda, aproibição de abuso de poderes processuais, ou o abuso de direito, como comportamento violador da boafé objetiva. Para Cristiano Chaves de Farias e Nel son Rosenvald, “o abuso de direito é constatado no instante da violação do elemento axiológico da norma. Instala-se a contrariedade entre o comportamento comissivo ou omissivo do indivíduo e o fundamento valorativo-material do preceito"60. Ainda no entender dos mencionados autores, que citam Heloísa Carpena, para a caracterização do ato abusivo é preciso extrair o "motivo legítimo das condições objetivas nas quais o direito foi exercido"61. Para Coutinho de Abreu, "há abuso de direito quando um comportamento aparentando ser exercício de um direito, se traduz na não realização dos interesses pessoais de que esse direito é instrumento e na negação de interesses sensíveis de outremp2. Como exemplo, podemos citar o abuso do direito de defesa, que, como já di to, podeautorizar a anteci pação dos efeitos da tutela (art.273, II , do CPC brasileiro, já transcrito acima), o abuso do direito de recorrer, que, no CPC brasileiro é

\footnotetext{
60 ROSENVALD, NelsoneFARIAS, Cristiano Chaves de. Direito Civil - TeoriaGeral. Rio deJ aneiro: Editora Lumen J uris, 2007, PP.508.

61 ROSENVALD, NelsoneFARIAS, Cristiano Chaves de. Direito Civil - TeoriaGeral. Rio deJ aneiro: Editora Lumen J uris, 2007, PP.510.

62 ABREU, J orge Manuel Coutinho de. Do abuso de direito. Coimbra: Almedina, 2006 (reimpressão), pp. 43.
} 
hi pótese expressa de litigância de máfé́ $e^{33}$.

Por fim, elenca a doutrina a denominada supressio, como elemento integrantedo princípio daboaféobjetiva, que podeser definida como a perda de poderes processuais em razão do seu não-exercício por tempo suficiente para incutir no outro sujeito a confiança legítima de que esse poder não mais seria exercido ${ }^{64}$. Como exemplo, podemos citar a supressio do poder do juiz de controlar a admissi bilidade do processo, se não o fez durante certo tempo, que levasse os demais sujeitos do processo a acreditar que este estava regular.

Assim, como destaca mais uma vez Fredie Didier Jr., percebesequeo princípio da boa-féobjetivaéa fontenormativa da proibição do exercício inadmissível de posições jurídicas processuais, que podem ser reuni das sob a rubrica do "abuso do direito" processual. Além do que, o princípio em comento torna ilícitas as condutas processuais levadas a cabo imbuídas de má fé, ou seja, sem boafé subjetiva, implicando, assim, o dever de o suje to processual não atuar commáfé, considerada esta como fato integrante do suporte fático de al guns ilícitos processuais. Esta é, Portanto, a relação entre boafé processual objetiva e subjetiva. A tente-se, porém, para o fato dequeo princípio éo da boafé objetiva processual, que, além de mais amplo, éa fonte dos demais deveres, inclusive o de não agir commá-féés.

\footnotetext{
$63 \quad$ Art. 17, II, do CPC játranscrito acima.

64 DIDIER J R., Fredie. Curso de Direito Processual Civil, Vol. I. Salvador: J usPodivm, 2009, pp.47.

65 DIDIER J R., Fredie. Curso de Direito Processual Civil, Vol. I. Salvador: JusPodivm, 2009, pp.48.
} 
Passemos, então, à busca pel o fundamento constitucional do princípio da boafféobjetiva. Aindaquenão existisse previsão expressa no sistema jurídico infraconstitucional brasileiro, o princípio poderia decorrer de outros princípios constitucionais. Isto porque, a exigência de comportamento em conformidade com a boa-fé pode ser encarada como conteúdo de outros direitos fundamentais ${ }^{66}$.

Para al guns autores ${ }^{67}$, o fundamento constitucional do princípio da boafé objetiva estaria no inciso I, do art. $3^{\circ}$, da Constituição brasileira, ao sustentar que éobjetivo da República Federativa do Brasil a construção de uma sociedade livre, justa e solidária. Haveria, portanto, um dever fundamental de solidariedade, do qual decorreria o dever de não quebrar a confiança e de não agir com deslealdade. Há, ainda, quem aponte a dignidade da pessoa humana como fundamento do princípio da boa-fé objetiva ${ }^{68}$, conforme previsão constante do art. 1ํ, III, da Constituição Federal brasileira ${ }^{69}$.

Para Menezes Cordeiro, citado por Fredie Didier J r., a exigência de atuação de acordo com a boaffé decorre do direito fundamental à igualdade, já que, a pessoa que confie,

\footnotetext{
66 DIDIER J R., Fredie. Curso de Direito Processual Civil, Vol. I. Salvador: J usPodivm, 2009, pp.48.

67 VINCENZI, Brunela Vieira de. A boafé no processo civil. São Paul o: Atlas, 2003, p.163.

68 ROSENVALD, Nelson. Dignidade Humana e boafé no Código Civil. São Paulo: Saraiva, 2005, p. 186.

69 Art. oㅡ A República Federativa do Brasil, formada pela união indissolúvel dos Estados e Municípios e do Distrito Federal, constitui-se em Estado Democrático de Direito e tem como fundamentos:

III - a dignidade da pessoa humana;
} 
legitimamente, numcerto estado de coisas não pode ser vista se não tivesse confiado: seria tratar o diferente de modo igual ${ }^{70}$.

Parte da doutrina, entretanto, identifica no princípio do contraditório o fundamento do princípio da boa-fé objetiva processual. Isto porque o contraditório, que não é apenas fonte de direitos processuais, mas também de deveres, não se presta apenas a dar aos litigantes o direito de poder influenciar na decisão, mas também tem uma finalidade de colaboração com o exercício da jurisdiçã̃o ${ }^{71}$. O direito ao contraditório não pode ser exercido ilimitadamente: o respeito à boafé objetiva é exatamente um desses limites ${ }^{72}$.

Já para J oan Pico i J unoy, citado por Fredie Didier J $\mathrm{r}^{73}$, o princípio da boafé processual compõe a cláusula do devido processo legal, limitando o exercício do direito de defesa, como forma de proteção do direito à tutela efetiva, do próprio direito de defesa da partecontrária e do di reito a um processo com todas as garantias, ou seja, devido. Cria, assim, a expressão devido processo leal.

Na mesma linha segue o Supremo Tribunal Federal brasileiro, ao reconhecer que o princípio do devido processo legal exige um processo leal e pautado na boafé, como se

\footnotetext{
70 DIDIER J R., Fredie. Curso de Direito Processual Civil, Vol. I. Salvador: J usPodivm, 2009, pp.48.

71 VINCENZI, Brunela Vieira de. A boafé no processo civil. São Paulo: Atlas, 2003, p.172.

72 DIDIER J R., Fredie. Curso de Direito Processual Civil, Vol. I. Salvador: JusPodivm, 2009, pp.49.

73 DIDIER JR., Fredie. Curso de Direito Processual Civil, Vol. I. Salvador: J usPodivm 2009, pp.49.
} 
observa do jul gado adi ante transcrito ${ }^{74:}$

O princípio do devido processo legal, que lastreia todo o lequedegarantiasconstitucionaisvol tadasparaaefetividade dos processos jurisdicionais e administrativos, assegura que todo jul gamento seja real izado com a observância das regras procedi mentais previamente estabelecidas, e, além, representa uma exigência defair trial, no sentido de garantir a participação equânime, justa, leal, enfim, sempre imbuída pela boa-fé e pela ética dos sujeitos processuais.

A máxima do fair trial é uma das faces do princípio do devido processo legal positivado na Constitui ção de 1988, a qual assegura ummodel o garantista dejurisdiç̧ão, vol tado para a proteção efetiva dos di reitos individuais e coletivos, e que depende, para seu pleno funcionamento, da boa fé e leal dade dos sujeitos que dele participam, condição indispensável paraa correção el egitimidadedo conjunto de atos, relações e processos jurisdicionais e admini strativos.

\section{E finaliza a Corte Suprema brasileira, ao destacar que o princípio daboaféobjetivaatingeatodosossujeitos processuais, e não apenas as partes:}

Nesse sentido, tal princípio possui umâmbito de proteção alargado, queexigeofairtrial não apenas dentreaqueles que fazempartedarelação processual, ou queatuamdiretamente no processo, mas de todo o aparato jurisdicional, o que abrange todos os sujeitos, instituições e órgãos, públicos e privados, que exercem, direta ou indiretamente, funções qualificadas constitucionalmente como essenciais à Justiça.

74 RE n. 464.963-2-GO, STF, 2a. Turma, rel. Min. Gilmar Mendes, julgado em 14.02.2006, publicado em no DJ de 30.06.2006. 
Ainda que se reconheça que todas as opções tratadas acima estejam corretas, concordamos com o posicionamento do Supremo Tribunal Federal brasileiro, levando em conta o fato de que a construção doutrinária do devido processo legal como uma cláusula geral é pacificamente aceita pela jurisprudência brasileira. Com base em tal pensamento, construiu-se nos Estados Unidos o dever de boafé processual como decorrência do fair trial75, o que torna mais fácil argumentar a existência de um dever geral de boafé processual como conteúdo do devido processo legal ${ }^{76}$.

\section{CONCL USÃO}

De acordo com o que foi apresentado no presente estudo, pode-se concluir que a virada hermenêtica promovida pelo neoconstitucionalismo, representada, embora não exclusivamente, mas principalmente pelo reconhecimento de nomatividade e supremacia aos princípios constitucionais, promoveu uma superação do conceito tradicional do processo, atrelado ao modelo formalista caracteŕstico do positivismo jurídico.

Tal pode ser observado pela utilização cada vez mais constante dos princípios constitucionais e das cláusulas gerais como fundamento normativo das soluções de conflitos, bem

$\overline{75}$ VINCENZI, Brunela Vieira de. A boafé no processo civil. São Paul o: Atlas, 2003, p.121.

76 DIDIER J R., Fredie. Curso de Direito Processual Civil, Vol. I. Salvador: JusPodivm, 2009, pp.50. 
como parâmetros de argumentação jurídica na mais recente doutrina processual. Isto porque, dianteda abertura característica de tais estruturas nomativas, estas apresentam-se mais aptas a acompanhar a evol ução e o aprimoramento das relações jurídicas e dos próprios di reitos fundamentais.

Conclui-se, portanto, nesse contexto, que a boafé surge no processo, em sua faceta objetiva, como princípio jurídico que vai servir de parâmetro de correção e honestidade em todas as relações jurídicas, principalmente processuais. Para que isso ocorra, entretanto, é preciso reconhecer ao princípio da boafé objetiva caráter técnico e normativo, impedindo que seja utilizado apenas como referência ética e metajurídica, sem qualquer aplicação concreta. Somente assim o processo devido poderátornar-se, muito mais que legal, um processo leal. 


\section{REFERÊNCIAS BIBLIOGRÁFICAS}

ABREU, Jorge Manuel Coutinho de Do abuso de direito. Coimbra: Almedina, 2006 (reimpressão).

BARROSO, Luís Roberto. Interpretação e Aplicação da Constituição. São Paulo: Saraiva, 2003.

BOBBIO, Norberto. Teoria do Ordenamento Jurídico. Brasília: Editora UnB, 1999.

BONAVIDES, Paulo. Curso de Direito Constitucional. São Paulo: Malheiros, 1994.

CANOTILHO, J.J. Gomes. Direito Constitucional e Teoria da C onstituição, 7ạ Edi ção. Coimbra: Almedina, 2003.

CARVALHO, Raquel Melo Urbano de Curso de Direito Administrativo. Salvador: J usPodivm, 2008, PP.110.

DIDIER JR., Fredie. C urso de Direito Processual Civil, Vol. I. Salvador: J usPodivm, 2009.

ESPÍNDOLA, Ruy Samue. Conceito de Princípios Constitucionais. São Paulo: Editora Revista dos Tribunais, 2002. 
FREIRE, Ricardo Mauńcio. 0 princípio constitucional da dignidade da pessoa humana. São Paulo: Saraiva, 2010.

MARINONI, Luiz Guilherme. Curso de Direito Processual Civil, Vol. I, Teoria Geral do Processo. São Paulo: Editora Revista dos Tribunais, 2006.

MENDONÇA JR., Delosmar. Princípio Constitucional da Duração Razoável do Processo, in Constituição e E fetividade Constitucional. Sal vador: J usPodivm, 2008, PP.27.

RIZZATTONUNES. 0 Princípio C onstitucional da Dignidade da Pessoa H umana. São Paulo: Saraiva, 2010.

ROSENVALD, Nelson. Dignidade Humana e boa-fé no Código Civil. São Paulo: Saraiva, 2005.

e FARIAS, Cristiano Chaves de. Direito Civil

- Teoria Geral. Rio de Janero: Editora Lumen Juris, 2007, PP.508.

VINCENZI, Brunela Vieira de A boa-fé no processo civil. São Paul o: Atlas, 2003. 